\title{
Dissociation and Compulsive Eating
}

\author{
Judy Lightstone, MA, MS
}

\begin{abstract}
Numerous investigators have noted a correlation between compulsive eating patterns and dissociative symptoms, but there is no systematic explanation for how these two phenomena interact. It is not uncommon for patients with compulsive eating patterns to experience previously dissociated memories of abuse and trauma, but there are no generally accepted interventions that address both the eating disorder and the traumatic experience. Furthermore, there are no commonly accepted guidelines for assessing trauma and dissociative symptoms in the many patients with intractable compulsive eating symptoms who may initially present with no traumatic history. This article presents theoretical formulations, a review of relevant research, and a model that suggests a causal relationship between dissociation and compulsive eating. Guidelines for assessment and intervention are proposed. The theoretical constructs in this paper are based on hunger-based symptom assessment and a feminist interpretation of object relations theory as it applies to compulsive eating and body shame. [Article copies available for a fee from The Haworth Document Delivery Service: 1-800-HAWORTH. E-mail address: $<$ docdelivery@haworthpress.com> Website: <http://www.HaworthPress.com> (C) 2004 by The Haworth Press, Inc. All rights reserved.]
\end{abstract}

KEYWORDS. Dissociation, compulsive eating, bulimia, anorexia, binge eating disorder, body shame, traumatic shaming, feminist object relations

Compulsive eating-repetitive bouts of compelled eating or restricting that are out of relation to physiological hunger and satiation-has

Judy Lightstone is affiliated with the California Institute of Integral Studies, San Francisco, CA.

Address correspondence to: Judy Lightstone, MA, MS, 2315 Prince Street, Berkeley, CA 94705 (E-mail: JudyLMFT@ comcast.net).

Journal of Trauma \& Dissociation, Vol. 5(4) 2004

http://www.haworthpress.com/web/JTD

(C) 2004 by The Haworth Press, Inc. All rights reserved.

Digital Object Identifier: 10.1300/J229v05n04_02 
been explored for decades and this literature spans the gamut of theories of etiology and treatment approaches. From the early family systems approaches of Mara Selvini Palazzoli (1974) and Salvador Minuchin (Minuchin, Rosman, \& Baker, 1978), to the pioneering psychoanalytic work of Hilde Bruch (1979) and Craig Johnson (Johnson \& Connors, 1987), to the feminist psychoanalytic theories and approaches of Kim Chernin (1981), Susie Orbach (1978) and Susan Wooley (Wooley \& Wooley, 1979), to the cognitive behavioral studies of Stewart Agras (Apple \& Agras, 1997), experts have been trying to understand the increasing prevalence, and the lethality and tenaciousness of compulsive eating symptoms, particularly among girls and women.

Numerous clinicians and investigators have observed an association between eating disorders and dissociation (Bloom, Gitter, Gutwill, Kogel, \& Zaphiropoulos, 1994; Kearney-Cooke, 1988; McNevin \& Rivera, 2001; Sands, 1991; Torem, 1990, 1993; Vanderlinden \& Vandereycken, 1988, 1997; Wooley \& Kearney-Cooke, 1986). The research literature on the overlap between compulsive eating problems and trauma is even more extensive, although there have been some contradictory findings. Most investigators have found a high correlation between the two (Brown, Russell, Thornton, \& Dunn, 1999; Dalle, Grave, Rigamonti, Todisco, \& Oliosi, 1996; Demitrack, Putnam, Brewerton, Brandt, \& Gold, 1990; Jacoby, Braks, \& Köpp, 1997; Johnson \& Connors, 1987; Lipschitz, Winegar, Hartnick, Foote, \& Southwick, 1999; McFarlane, McFarlane, \& Gilchrist, 1988; Oppenheimer, Howells, Palmer, \& Chaloner, 1986; Runtz \& Briere, 1986; Sanders, 1986; Spiegel, 1986; Torem, 1986; Vanderlinden Vandereycken, \& Probst, 1995; Wooley \& Kearney-Cooke, 1986). Everill and Waller (1995) came to similar conclusions in a literature review that summarized 84 studies. Only two investigations have shown a low correlation (Korte, Horton, \& Graybill, 1998; Nagata, Kiriike, Iketani, Kawarada, \& Tanaka, 1999), and Nagata et al. studied a non-Western population in Japan.

Two interesting studies, one by Jacoby et al. (1997) and the second by Brewerton, Dansky, Kilpatrick, \& O'Neil (1999) have elucidated the importance of timing in determining a history of trauma in eating disorder patients. Jacoby et al. found that after questioning 748 women with compulsive eating problems before inpatient hospitalization and then again 2.7 years after treatment, the reported incidence of sexual abuse doubled. Brewerton et al. (1999) posed similar questions in their study and also found that amnesia for sexual abuse is quite common early in treatment, especially among bulimics. 
Most research on this topic does not attempt to explain a causal relationship between compulsive eating and dissociated trauma. However, in a theoretical article, Bromberg (2001) considered some possibilities. Primarily in reference to compulsive starvation, he stated:

... The central issue for an eating disordered patient is that she is at the mercy of her own physiologic and affective states because she lacks an experience of human relatedness and it's potential for reparation that mediates self-regulation. She is enslaved by her felt inability to contain desire as a regulatable affect . . . Trauma compromises trust in the reparability of relationship ... (p. 891)

Recent investigations concerning somatoform dissociation further suggest that eating disorders and dissociation may be highly correlated. In a comparison of the Dissociative Experiences Scale (DES) and the five item version of the Somatoform Dissociation Questionnaire (SDQ-5), Nijenhuis (1999) notes the greater sensitivity of the SDQ in picking up dissociation in patients with eating and somatoform disorders: ". . . 40\% of the cases with eating disorder . . . passed the SDQ-5 cutoff ... [for dissociative disorder]" (p. 75), in contrast to no significant DES scores for these patients. On another interesting note, the SDQ also proved to be a more sensitive device in screening for dissociative disorders in patients who were not aware of their diagnoses, whereas "DID patients who were unaware of their diagnostic status obtained lower DES scores than DID patients who were knowledgeable of their condition" (p.74).

Somatoform dissociation and eating disorders may be linked to unconscious and unspoken distress. Just as many women in Freud's day manifested their unspeakable experiences in the conversion to bodily symptoms of hysteria, today large numbers of women and men are trying to speak symbolically through the language of compulsive eating and body image disturbances. I hypothesize that in many instances, compulsive eating effectively disguises dissociated, dismissed or denied experiences of trauma or abuse due to the need to disavow the abuse and because of the cultural acceptance of concerns about eating and weight.

THE ANTI-DEPRIVATION APPROACH TO COMPULSIVE EATING AS A MODEL FOR ASSESSMENT OF DISSOCIATION

Compulsive eating is defined here as repetitive bouts of compelled eating or restricting that are out of relation to physiological hunger and 
satiation. This definition, first used by Orbach (1978), is not based on the number of calories consumed, and differentiates some forms of high caloric consumption from disordered eating. For example, someone who has been starved could consume a great many calories but would not be considered to be eating compulsively. Notably, this definition is at odds with many behaviorally based eating disorder programs that prescribe "three moderate meals per day" and/or a dietician-designed food plan, without regard to hunger and satiation.

In determining normal versus disordered eating, it is also problematic that "ideal" body weight is still being based on the weight and height chart developed in 1983 by the insurance actuaries at Metropolitan Life Insurance Company (1983), based on the lowest mortality rate for men and women ages 25-59. The scientific validity of this chart is highly questionable at best, considering that it disregards the wide range of "normal" in the population at large and many complex health variables. Varying metabolism, activity levels, or individual health, environmental, or genetic differences are not taken into account. Increasingly, studies are showing weight to be determined by all of these variables, many of which are not consciously controlled (Coady et al., 2002; Hebebrand et al., 2000; Heitmann, Harris, Lissner, \& Pedersen, 1999; U.S. Department of Health and Human Services, 1996; Verga, Buscemi, \& Caimi, 1994).

The Body Mass Index (BMI), a more modern version of the above standard-bearer for assessment of obesity, is similarly problematic. The BMI, like the Metropolitan Height and Weight charts, makes no distinction between muscle weight and fat weight:

One problem with using BMI as a measurement tool is that very muscular people may fall into the "overweight" category when they are actually healthy and fit. Another problem with using BMI is that people who have lost muscle mass, such as the elderly, may be in the "healthy weight" category-according to their BMI-when they actually have reduced nutritional reserves. BMI, therefore, is useful as a general guideline to monitor trends in the population, but by itself is not diagnostic of an individual patient's health status. (National Institutes for Health, 2001)

And, according to Gallagher, Testolin, Heshka, and Heymsfield (n.d.): ". . . misclassification of fatness by BMI may occur in over one-fourth of healthy adults." 
A distinction between binge eating disorder and obesity is rarely made in the research literature. Although most persons with binge eating disorder are overweight, the reverse is not the case, because obesity has many causes other than compulsive overeating. For example, obesity has been shown to have a significant genetic component according to cross-sectional twin and family studies done by Coady et al. (2002). And this genetic component is compounded by the tendency of obese people to mate with each other, as they are often excluded from mainstream dating circles:

Our results indicate that assortative mating is common among parents of extremely obese children and adolescents, ascertained between 1995 and 1997. In addition, the parental loading on the tenth decile is most prominent for the most obese children. (Hebebrand et al., 2000, p. 345)

Furthermore, obese people have been found to expend less energy while sleeping and resting than those who are not obese, making it easier to gain weight on lower caloric intake than those with higher resting energy expenditure rates:

Resting energy expenditure (REE) was investigated by indirect calorimetry in relation to body composition and to different degrees of obesity in order to assess if a defective energy expenditure contributes to extra body fat accumulation . . . The analysis showed a negative impact of obesity on REE beyond body composition variables. (Verga, Buscemi, \& Caimi, 1994, p. 47)

Additional causes of obesity unrelated to compulsive eating were also found by studies from the National Institutes for Health (2001) and by Heitmann, Harris, Lissner, and Pedersen (1999).

Because so many obese people do not have compulsive eating problems, the many studies that fail to find high correlations between a severe trauma history and obesity do not invalidate my hypothesis that compulsive eating is uniquely suited to cover up an abuse history. I propose that more research needs to be done in this area that excludes non-compulsive eaters from the populations of obese people usually used to assess correlations with dissociated trauma.

Imposing rigid, actuarial-based statistics on persons who have been shunned for being different (fat) since childhood only reinforces the abusive cultural and familial messages that have been internalized. Fol- 
lowing the patient's hunger and satiation patterns and eliminating externally imposed dietary regimens is a much more sensitive and accurate way to assess for compulsive eating and to rule out confounding factors when assessing for underlying trauma as in the following clinical example:

Patient: I had a huge binge last night.

Therapist: Were you hungry?

Patient: I was starving, but I couldn't stop eating. I was putting away food like I would never eat again-I just shoveled it in. It was disgusting.

Therapist: That is a normal way to eat when you are starving. How did you end up getting so hungry?

Patient: No. You didn't see it-there was nothing normal. I mean, I ate straight from the container-I didn't even bother to heat it up.

Therapist: You must have been terribly hungry. How did that happen?

Patient: Well, I had had such an awful binge the night before last that I decided I could go the next day without any food. I've done it many times before. But this time I was such a weakling.

Therapist: I don't agree. There's nothing "weak" or "bad" about feeding yourself when you are hungry. We would do better to explore this idea that you have to starve yourself any time you have what looks to you like a compulsive eating episode. Some of these "binges" may be perfectly normal reactions to abnormal deprivation. In order to work through the actual compulsive eating episodes, we must first be able to distinguish them from "binges" that are in response to deprivation. The only way to be sure is to ask yourself if you are physically hungry first. If the answer is "yes" because it has been a while since you have eaten, then the work would be to try to just enjoy your food.

People with compulsive eating problems then, eat and/or starve compulsively on a consistent basis over time and feel terrible shame about both the behavior and the effects of this behavior (perceived or real) on their body size. In fact, each compulsive eating episode tends to be accompanied by the process described in the cycles below. The process 
varies to some degree based on whether the problem is binge eating disorder, anorexia, chronic dieting or bulimia; however, the overall patterns are more similar than different. In this way, the chronic yo-yo dieter has a similar pattern to a bulimic, only the "purge" of the restrictive diet would last days, weeks or months as opposed to the bulimic purge which takes a few minutes or hours.

For the sake of clarity, I will define a restrictive diet as any externally imposed food plan (whether it is some fad diet or a plan prescribed by a dietitian) that ignores hunger and satiation rhythms and sensations. It might be helpful to keep in mind, as we Americans are so fond of restrictive diets, that the amount that has been determined by the World Health Organization to be needed to maintain adequate nutrition and health is a minimum of 2,000-2,500 calories per day.

\section{SHAME, COMPULSIVE EATING AND DISSOCIATION}

Shame can be one of the earliest triggers for dissociative or freezing responses in the young child. In a healthy parent-child relationship, reproach helps the child to stay safe (e.g., "No! Don't touch that-it's hot!"), as well as conditioning the child to the culture's acceptable behavior (e.g., "No! Don't throw your food on the floor!"). Indeed, it has been proposed that non-traumatic shame is a major factor in the normal development of the self (Nathanson, 1987). I would define non-traumatic shame experiences as those that are not so painful or physically intrusive or culturally dystonic that they need to be denied or dissociated by the individual in order to be tolerated. Nathanson (1987) goes on to differentiate the defensive scripts that are intended to dissociate the experience of shame, for those who cannot tolerate normal shaming experiences in adulthood, from those meant simply to decrease it's impact. Unlike those who can tolerate shame because of healthy early attachment experiences, those who must avoid shame experiences at all cost may do so through the misuse of substances (such as food), or behaviors that allow them to attack themselves or others to feel more in control.

When the organism cannot modulate fear and distress . . . it attempts to inhibit the arousal through the central inhibitory mechanism-intrinsic shame affect. The combination of excess arousal and central inhibition (shame) blocks the information processing 
system ... [thereby triggering the dissociative response]. (Tomkins, 1962 referenced in Leeds, 2001, p. 23)

As can be seen in the Binge Cycle diagram in Figure 1, the binge may be triggered by an event or thought that is related to an earlier shaming and/or traumatic experience (consciously remembered or not). In this way, the food medicates the shame or the intrusive trauma symptoms at the same time as it redirects attention to the present eating behavior or corporeal self-experience, helping the patient to dissociate or dismiss any thoughts and feelings originally associated with them. If the binge and diet/purge cycles can be viewed as a traumatic reenactment, then it seems likely that the shame that was originally associated to the trauma gets displaced onto the body or the eating behavior. The earlier traumatic shaming experience is therefore transformed into the more culturally syntonic feeling of body shame (for women in particular), which leads to severe self-critical thoughts. At this point the person reaches for food to help salve the pain. The shaming thoughts are then redirected onto the eating behavior, which puts the eating in a paradoxical role. While it is soothing the person, it simultaneously provides the person with a socially accepted and culturally encouraged explanation for the now dissociated original cause for the shame. The eating then becomes the enemy, and is experienced as out of control self-destructive behavior

FIGURE 1

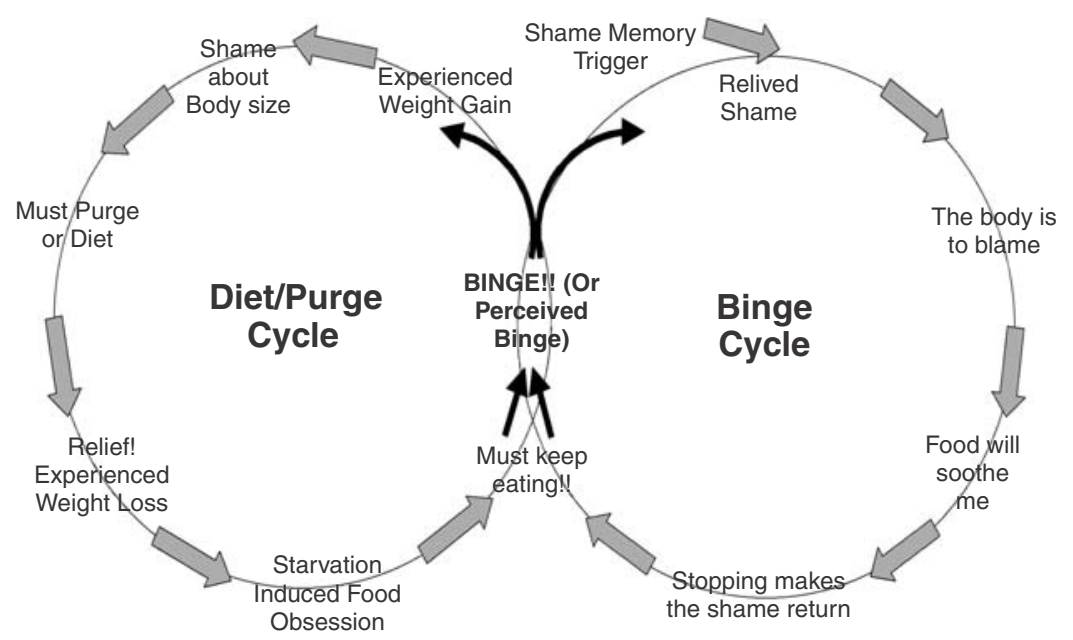


with no redeeming purpose. Because of the powerful paradoxical effect of the eating, it must continue or the feelings will return. Nevertheless, ultimately physiological pressures will force the eating to stop. The experience of being over-full then triggers the diet or purge cycle. By this time the original trigger is completely obliterated by the drama of the binge and purge or diet as in the following clinical example:

Therapist: What do you think made you go for the Oreos at 2p.m. yesterday?

Patient: Well, as you know, that's when I get home from my job, and then I have an hour to get to class. I always binge then. I have trouble with transitions.

Therapist: Yes that seems to be a hard time of the day. Can you remember what made it so hard yesterday?

Patient: I'm just stupid . . . it's stupid, that's all. I used to see Joey during my break when we lived together . . . but that was so long ago and so that can't still be it.

Therapist: So you feel ashamed about still missing Joey? You should be over it by now?

Patient: I never get over anything. I'm so clingy and needy-no wonder he left me.

Therapist: So remembering that you used to see Joey then reminds you of the shame you feel for still needing him?

Patient: It makes me sick to think about it.

Therapist: Is that why you reached for the Oreos, do you think? Because of that sick feeling?

Patient: Yes, but they just make me feel sicker! It doesn't make sense!

Therapist: Well it kind of makes sense if you wanted to forget the sick feeling about Joey, that you might cover it with a sick feeling about eating, which maybe doesn't feel as shameful.

Patient: But it does! I'm nothing but a big fat cow! All I do is stuff cookies to get fatter. Ugh!

In this example (is) the shame originally associated with her "clinging"-likely once an expectable reaction to abandonment or emotional neglect, then later reenacted with her boyfriend-is now reattached to the relatively familiar and socially acceptable arena of her body. From feeling isolated and humiliated by her neediness, she now joins the throngs of women who think they're too fat. This feeling, although dysphoric, is clearly more tolerable and ego syntonic. However, over time, as the pa- 
tient grows to trust the therapist and see the patterns repeatedly she may wonder why feeling clingy is so triggering, and may eventually associate it to the disrupted and anxious attachment to an abusive or abandoning parent.

The hunger-based approach results in a cure of the compulsive eating, rather than mere symptom reduction. This is because more standard behavioral approaches that simply seek to document weight gain or loss and a reduction in binges usually do not uncover the traumatic reenactments against the body. When the trauma is not identified, it cannot be treated, and so the disorder can only be managed at best. This is similar to the difference between a treatment for dissociation that only looks at cognitive distortions and one that works with the patient's parts or alters-the former will most likely not get to the underlying trauma, whereas the later will. To achieve a cure of compulsive eating then, any underlying, significant trauma must be identified and processed, as is the case with persons with both substance abuse and trauma (Najavits, Weiss, Shaw, \& Muenz, 1998).

\section{OBJECT RELATIONS AND EATING DISORDERS}

In object relations theory, introjects are the internalizations of aspects of the developing child's external interpersonal relationships. So, when compulsive eaters have introjects that see the self as defective or despised (fat), it can be surmised that actual early relationships may have been abusive or traumatic. Kernberg (1997, p. 701) notes, "Trauma as the actual experience of sadistic behavior of a needed, inescapable object instantaneously shapes the rage reaction into the hatred of the sadistic object." The behavior of patients towards food, in their restricting, eating and purging compulsions, can then be seen as representing a reenacted relationship to a hated yet needed other-someone the patient could not escape because she needed this person too much, someone who kept her alive, though in misery.

Susan Gutwill (1989) presented at a conference for the Women's Therapy Centre Institute in which she applied a feminist interpretation of the object relations approach to the treatment of bulimia. Gutwill detailed her process of reviewing and reliving each binge/purge episode with her patient "Lily," as they revealed the dissociated and symbolic memories of past abuse. In her disordered eating, Lily reenacted the process of searching for the all-nurturing mother in the food, which turned bad as it forcefully and brutally invaded her body, only to be ritu- 
ally exorcised by the purge at the end. By slowing down and listening to the details of the symptoms, Gutwill was able to hear what Lily couldn't tell her (or herself) initially in words. By elucidating the feelings and thoughts moment by moment inside the symptom, Lily was able to describe a purge that was both urgent and orgiastic, both relief and torture, crying, "It hurts! It hurts in my woman parts ... it hurts to be a woman ... I must get this out of me!" Gradually the story unfolded that Lily's mother used her as a child prostitute to support her drug habit. This is only one example of how sadistic introjects may present themselves for treatment via compulsive eating. The intense ambivalence about food that is so common often symbolizes the splitting that the child had to do in order to preserve an image of a loving internalized caretaker apart from the reality of an abusive or neglectful caretaker. This splitting is acted out through the patterns that alternate bingeing with dieting or purging.

Much productive work can be done with patients in translating symbolic behavior into verbal communication, to allow the "unspeakable" to be heard and understood. A therapist might ask the patient to "speak to the fat" (or perceived fat) or to allow the "fat to speak" to her. The following are typical statements when "the fat" is allowed to "talk"-the answers demonstrate the language of a protector or rescuer part or alter, a perpetrator part, and a victimized child part:

"I'm here to protect you ... to keep the men away from you."

"I'm all over your body-I'm going to suffocate you."

"Why do you blame me for everything? Why do you hate me so? You created me!"

Similarly, when patients are asked to imagine what it was like to be fatter or thinner then they are now, they respond with the language of defenses and coping strategies:

"When I was thin I had no boundaries-I'd go after men shamelessly."

"When I was fat I would hide behind it. If someone didn't like me, I could blame it on the fat."

"I felt myself getting so fat . . . like I was blowing up like a balloon and floating away." 
Clinicians should exercise caution and judgment in the evaluation of compulsive eating, which can derive from a variety of etiologies. Not all disordered eating symptoms can or should be translated into trauma or abuse experiences. This is why therapists must listen to the language the patient uses. Do the binges sound trance-like and punishing or embodied and soothing? Is the relationship to the body sadistic or mildly rejecting? Table 1 is a chart of some of the distinctive symptoms and metaphors that are commonly heard from compulsive eating patients, and how they may help in the assessment for trauma and dissociation. However, it should be emphasized that these characteristics should not be the sole basis for determining whether a patient has a dissociative disorder or history of trauma; such determinations should be based on a comprehensive clinical evaluation.

\section{CONCLUSIONS}

Compulsive eating problems may be a phenomenon in our time and culture as hysteria was in Freud's time and culture. Dissociation may play a central mechanism in which feelings from past traumatic experiences are projected onto the self and disordered eating. Many people in Western society seem to have opted for splitting off the intolerable and projecting it onto "fat." Our society's rage against fat as sin may be

TABLE 1. Considering the dissociative bases for compulsive eating symptoms.

\begin{tabular}{|c|c|c|}
\hline Symptom & May Be Dissociative & Not Necessarily Dissociative \\
\hline Binges & Punishing trance-like binges & Aware during binges \\
\hline Bulimia & $\begin{array}{l}\text { Punishing or ecstatic trance-like } \\
\text { purges }\end{array}$ & Least pain for maximum "gain" \\
\hline $\begin{array}{l}\text { Body Image } \\
\text { Distortions }\end{array}$ & $\begin{array}{l}\text { "The person in mirror is not me } \\
\ldots \text { is someone else" } \\
\text { Fear of reflection }\end{array}$ & $\begin{array}{l}\text { "The fat is ugly-I hate it" } \\
\text { Loathing the fat/self } \\
\text { Disgust at reflection }\end{array}$ \\
\hline Anorexia & $\begin{array}{l}\text { Unable to feel hunger } \\
\text { Does not see self in mirror - } \\
\text { does not see emaciation }\end{array}$ & Fights but denies hunger pangs \\
\hline $\begin{array}{l}\text { Meaning of Body } \\
\text { Size }\end{array}$ & $\begin{array}{l}\text { Fat and thin selves behave and } \\
\text { think very differently; one cannot } \\
\text { control the other }\end{array}$ & $\begin{array}{l}\text { Fat and thin selves feel very } \\
\text { differently but behavior and } \\
\text { thinking do not change much }\end{array}$ \\
\hline $\begin{array}{l}\text { Fat/Thin Fantasy } \\
\text { Response }\end{array}$ & $\begin{array}{l}\text { Fat is experienced as hiding self } \\
\text { or as floating or flying away }\end{array}$ & $\begin{array}{l}\text { Fat self experienced as visible and } \\
\text { heavy or weighed down }\end{array}$ \\
\hline
\end{tabular}


comparable to the Victorian attitude about sex (Orbach, 1986). Our female children are expected to welcome their newly blossoming womanhood with a diet, and we seem to have turned our most basic life sustenance into a seductive, manipulative or abusive enemy. Americans' desperation to avoid the stigma of fat is reflected in how we spend our money:

Americans spend $\$ 33$ billion annually on weight-loss products and services. This figure represents consumer dollars spent in the early 1990s on all efforts at weight loss or weight maintenance including low-calorie foods, artificially sweetened products such as diet sodas, and memberships to commercial weight-loss centers. (Colditz, 1992)

Compulsive eating speaks to the ambivalent aspects of consumerism, and may also function as displaced reenactments of dissociated abuse.

Compulsive eating can obscure a trauma history from the clinician and the patient, (and) resulting in high treatment resistance and relapse rates. Success in clinical practice to help some patients permanently get beyond their compulsive eating symptoms can be enhanced by a number of factors: (1) If histories of trauma and dissociative symptoms are present, patients and therapists must be aware of the role of dissociation in disordered eating, including somatoform dissociation. (2) Therapists can use the anti-deprivation approach to overcoming the compulsive eating symptoms, rather than simply emphasizing behavioral treatments of eating symptoms that ignore the foundation of the bodily cues of hunger and satiation. Obesity should not be equated with compulsive overeating. (3) Integrating a feminist object relational approach to working with compulsive eating problems may reveal crucial insights about patients' early attachments and their fundamental assumptions about themselves and how they relate to the outside world.

\section{REFERENCES}

Apple, R. F., \& Agras, W. S. (1997). Overcoming eating disorders: A cognitive-behavioral treatment for bulimia nervosa and binge eating disorder, Patient workbook. San Antonio, TX: The Psychological Corporation.

Bloom, C., Gitter, A., Gutwill, S., Kogel, L., \& Zaphiropoulos, L. (1994). Eating problems: A feminist psychoanalytic treatment model. New York: Basic Books. 
Brewerton, T.D., Dansky, B.S., Kilpatrick, D.G., \& O’Neil, P.M. (1999). Bulimia nervosa, PTSD, and forgetting: Results from the National Women's Study. In L.M. Williams, \& V.L. Banyard (Eds.), Trauma and memory (pp. 127-138). Thousand Oaks, CA: Sage Publications.

Bromberg, P.M. (2001). Treating patients with symptoms-and symptoms with patients: Reflections on shame, dissociation and eating disorders. Psychoanalytic Dialogues, 11, 891-912.

Brown, L., Russell, J., Thornton, C., \& Dunn, S. (1999). Dissociation, abuse and the eating disorders: Evidence from an Australian population. Australian and New Zealand Journal of Psychiatry, 33, 521-528.

Bruch, H. (1979). The golden cage. New York: Random House.

Chernin, K. (1981). The obsession: Reflections on the tyranny of slenderness. New York: Harper \& Row.

Coady, S.A., Jaquish, C.E., Fabsitz, R.R., Larson, M.G., Cupples, L.A., \& Myers, R.H. (2002). Genetic variability of adult body mass index: A longitudinal assessment in Framingham families. Obesity Research, 10, 675-681.

Colditz, G.A. (1992). Economic costs of obesity. American Journal of Clinical Nutrition, 55, 503-507.

Dalle, G.R., Rigamonti, R., Todisco, P., \& Oliosi, E. (1996). Dissociation and traumatic experiences in eating disorders. European Eating Disorders Review, 4(4), 232-240.

Demitrack, M.A., Putnam, F.W., Brewerton, T.D., Brandt, H.A., \& Gold, P.W. (1990). Relation of clinical variables to dissociative phenomena in eating disorders. American Journal of Psychiatry, 47, 1184-1188.

Everill, J.T., \& Waller, G. (1995). Reported sexual abuse and eating psychopathology: A review of the evidence for a causal link. International Journal of Eating Disorders, 18(1), 1-11.

Gallagher, D., Testolin, C., Heshka, S., \& Heymsfield, S.B. (n.d.). Body mass index: Differential misclassification of under and over-fatness. New York City: Obesity Research Center, St. Luke's-Roosevelt Hospital Center, Columbia University. Retrieved October 7, 2003 from http://www.healthchecksystems.com/tbmi.htm.

Gutwill, S. (1989). "Lily": A case of bulimia nervosa. Paper presented at the Women's Therapy Centre Institute Symposium, New York City.

Hebebrand, J., Wulftange, H., Goerg, T., Ziegler, A., Hinney, A., Barth, N., Mayer, H., \& Remschmidt, H. (2000). Epidemic obesity: Are genetic factors involved via increased rates of assortative mating? International Journal of Obesity Related Metabolic Disorders, 24, 345-353.

Heitmann, B.L., Harris, J.R., Lissner, L., \& Pedersen, N.L. (1999). Genetic effects on weight change and food intake in Swedish adult twins. American Journal of Clinical Nutrition, 69, 597-602.

Jacoby, G.E., Braks, K., \& Köpp, W. (1997). Reports on sexual abuse by eating-disordered women before and after psychotherapy: A comparison of anamnestic and catamnestic data. European Eating Disorders Review, 5(3), 171-183.

Johnson, C., \& Connors, M. (1987). The etiology and treatment of bulimia nervosa: A biopsychosocial perspective. New York: Basic Books.

Kearney-Cooke, A. (1988). Group treatment of sexual abuse among women with eating disorders. Women and Therapy: A Feminist Quarterly, 7(1), 5-23. 
Kernberg, Otto F. (1997). Aggression, trauma, and hatred in the treatment of borderline patients. Personlichkeitsstorungen: Theorie und Therapie, 1, 15-23.

Korte, K.L., Horton, C.B., \& Graybill, D. (1998). Child sexual abuse and bulimic behaviors: An exploratory investigation of the frequency and nature of a relationship. Journal of Child Sexual Abuse, 7(1), 53-64.

Leeds, A. M. (2001). Strengthening the self: Principles and procedures for creating successful treatment outcomes for adult survivors of neglect and abuse. Santa Rosa, CA: Author. (Cassette recording and manual available from Andrew M. Leeds, PhD, 1049 Fourth Street, Suite G, Santa Rosa, CA 95404).

Lipschitz, D.S., Winegar, R.K, Hartnick, E., Foote, B., \& Southwick, S.M. (1999). Posttraumatic stress disorder in hospitalized adolescents: Psychiatric comorbidity and clinical correlates. Journal of the American Academy of Child and Adolescent Psychiatry, 38, 385-392.

McFarlane, A.C., McFarlane, C.M., \& Gilchrist, P.N. (1998). Posttraumatic bulimia and anorexia nervosa. International Journal of Eating Disorders, 7, 705-708.

McNevin, S.H., \& Rivera, M. (2001). Obsessive compulsive spectrum disorders in individuals with dissociative disorders. Journal of Trauma \& Dissociation, 2(4), 117-131.

Metropolitan Life Insurance Company. (1983). Metropolitan height and weight tables. New York: Author.

Minuchin, S., Rosman, B., \& Baker, L. (1978). Psychosomatic families: Anorexia Nervosa in context. Cambridge, MA: Harvard University Press.

Nagata, T., Kiriike, N., Iketani, T., Kawarada, Y, \& Tanaka, H. (1999). History of childhood sexual or physical abuse in Japanese patients with eating disorders: Relationship with dissociation and impulsive behaviours. Psychological Medicine, 29, 935-942.

Najavits, L., Weiss, R., Shaw, S., \& Muenz, L. (1998). “Seeking Safety”: Outcome of a new cognitive-behavioral psychotherapy for women with post traumatic stress disorder and substance dependence. Journal of Traumatic Stress, 11, 437-456.

Nathanson, D. (1987). A timetable for shame. In D.L. Nathanson (Ed.), The many faces of shame (pp. 1-63). New York: Guildford Press.

Nathanson, D. (1998). Locating EMDR: Affect, scene and script. Paper presented at the EMDR International Association Conference, Baltimore, MD.

National Institutes for Health. (2001). Understanding adult obesity. NIH Publication No. 01-3680. Washington, DC: U.S. Government Printing Office.

Nijenhuis, E.R.S. (1999). Somatoform dissociation: Phenomena, measurement, and theoretical issues. Assen, The Netherlands: Van Gorcum.

Oppenheimer, R., Howells, K., Palmer, R.L., \& Chaloner, D.A. (1985). Adverse sexual experience in childhood and clinical eating disorders: A preliminary description. Journal of Psychiatric Research, 19, 357-361.

Orbach, S. (1978). Fat is a feminist issue: Parts I and II. New York: Paddington Press, Ltd.

Orbach, S. (1986). Hunger strike: The Anorectic's struggle as a metaphor for our age. New York: W.W. Norton \& Co.

Palazzoli, M.S. (1974) Self-starvation: From individual to family therapy in the treatment of anorexia nervosa. New York: Jason Aronson. 
Runtz, M., \& Briere, J. (1986). Adolescent "acting out" and childhood history of sexual abuse. Journal of Interpersonal Violence, 1, 326-334.

Sands, S. (1989). Eating disorders in female development: A self-psychological perspective. In A. Goldberg (Ed.), Dimensions of self-experience: Progress in self psychology (vol. 5). Hillsdale, NJ: The Analytic Press.

Sanders, S. (1986). The perceptual alteration scale: A scale measuring dissociation. American Journal of Clinical Hypnosis, 29(2), 95-102.

Sands, S. (1991). Bulimia, dissociation, and empathy: A self-psychological view. In C. Johnson (Ed.), Psychodynamic treatment of anorexia nervosa and bulimia (pp. 34-39). New York: Guilford Press.

Spiegel, D. (1986). Dissociating damage. American Journal of Clinical Hypnosis, 29(2), 123-131.

Tomkins, S.S. (1962). Affect imagery consciousness: The negative affects (vol. 2). New York: Springer Publishing Company.

Torem, M.S. (1986). Dissociative states presenting as an eating disorder. American Journal of Clinical Hypnosis, 29(2), 137-141.

Torem, M.S. (1990). Covert multiple personality underlying eating disorders. American Journal of Psychotherapy, 44, 357-368.

Torem, M.S. (1993). Eating disorders in patients with multiple personality disorder. In R.P. Kluft, \& C.G. Fine (Eds.), Clinical perspectives on multiple personality disorder (pp. 343-353). Washington: American Psychiatric Press.

U.S. Department of Health and Human Services, Centers for Disease Control and Prevention. (1996). Physical activity and health: A report of the surgeon general. Washington, DC: U.S. Government Printing Office.

Vanderlinden, J. \& Vandereycken, W. (1988). The use of hypnotherapy in the treatment of eating disorders. International Journal of Eating Disorders, 7, 673-679.

Vanderlinden, J. \& Vandereycken, W. (1997). Trauma, dissociation, and impulse control in eating disorders. Eating Disorders Monograph Series, No. 9. New York: Brunner/Mazel.

Vanderlinden, J., Vandereycken, W., \& Probst, M. (1995). Dissociative symptoms in eating disorders: A follow-up study. European Eating Disorders Review, 3(3), 174-184.

Verga, S., Buscemi, S., \& Caimi, G. (1994). Resting energy expenditure and body composition in morbidly obese, obese and control subjects. Acta Diabetologia, 31(1), 47-51.

Wooley, S.C., \& Wooley, O.W. (1979). Obesity and women-I. A closer look at the facts. Woman's Studies International Quarterly, 2, 69-79.

Wooley, S.C., \& Kearney-Cooke, A. (1986) Intensive treatment of bulimia and body image disturbance. In K. Brownell, \& J. Forey (Eds.), Physiology, psychology and the treatment of the eating disorders (pp. 477-502). New York: Basic Books.

RECEIVED: 01/14/03

REVISED: 09/21/03

$10 / 07 / 03$

ACCEPTED: 10/16/03 